\title{
Airplane transport isolators may loose leak tightness after rapid cabin decompression
}

\author{
Roland Albrecht ${ }^{1,2}$, Andres Kunz ${ }^{3}$ and Wolfgang G Voelckel ${ }^{4,5,6,7,8^{*}}$
}

\begin{abstract}
Air medical transport of patients suffering of highly infectious diseases is typically performed employing portable isolation chambers. Although the likelihood of decompression flight emergencies is low, sustainability of the devices used is crucial. When a standard isolation unit was subjected to an explosive cabin decompression of $493 \mathrm{hPa}$, simulating a $32808 \mathrm{ft}$ flight level accident, leak tightness of the unit was lost due to rupture of the bag caused by over expansion. When the pressure chamber experiment was repeated with a modified unit, distension was minimized by an additional compensation air bag, thus ensuring leak tightness.
\end{abstract}

Keywords: Air medical transport, Infectious diseases, Decompression, Isolation chamber

\section{To the Editor}

The current Ebola epidemic highlights air transport challenges of infectious patients. The Guidance on Air Medical Transport for Patients with Ebola Virus Disease published by the Centers for Disease Control and Prevention recommend a portable isolation unit to contain infected materials and minimize contamination of the aircraft. [1] At present, air carriers employ two different devices: smaller singleperson isolation units or the larger Aeromedical Biological Containment System, resembling a plastic tent. Under undisturbed flight conditions, both technologies have been shown feasible and effective in preventing contamination. When optimizing our transport protocol, we had to recognize that little is known about safety in case of flight emergencies such as rapid cabin decompression. Accordingly, we tested the effects of an explosive decompression on the sustainability of the chamber currently used in our program (VenIONPIU, TB-Safety Ltd., Frick, Switzerland).

Tests were performed at the Swiss Air Force Aeromedical Center in Dübendorf, Switzerland. In two hypobaric chambers, separated by a standard airplane window size membrane, pressures were adjusted to the typical pressure difference between in-cabin and ambient pressure at $22965,27886,32808$ and $33464 \mathrm{ft}$ flight level, respectively. To simulate an explosive decompression, the membrane

\footnotetext{
* Correspondence: wolfgang.voelckel@auva.at

${ }^{4}$ Department of Anesthesiology and Critical Care Medicine, AUVA Trauma

Center, Dr.-Franz-Rehrl-Platz 5, A-5010 Salzburg, Austria

${ }^{5}$ ÖAMTC Austrian Air Rescue, Vienna, Austria

Full list of author information is available at the end of the article
}

was cracked in four consecutive experiments, resulting in an immediate pressure drop of 360, 424, 493 and $500 \mathrm{hPa}$ (5.22, 6.15, 7.15 and 7.25PsI) within 1.5-3 seconds, respectively. The single-patient isolation unit was mounted on a stretcher as usual and monitored by video surveillance. For each of the first three tests, a new isolation unit was used, whereas in the fourth setting, reproducing a decompression scenario at $33464 \mathrm{ft}$ flight level, a modified unit with an additional air bag designed to compensate volume expansion was employed.

\section{Findings}

As defined by the law of Boyle and Mariotte, air volume within the patient isolation unit expanded with increasing $\Delta$ p by1.6-2.1, respectively, thus causing overexpansion of the bag (Additional file 1). In the third test when $\Delta \mathrm{p}$ was $493 \mathrm{hPa}$ (7.15PsI), leak tightness of the unit was lost due to a ruptured suture (Figures 1 and 2). When the experiment was repeated with the modified unit $(\Delta \mathrm{p}$ $500 \mathrm{hPa} / 7.25 \mathrm{PsI}$ ), distension of the patient chamber was minor due to the compensation air bag and leak tightness was maintained.

Although incidence of flight emergencies is low, decompression tests of isolation units should be mandatory in order to guarantee safety for air transport of patients with hemorrhagic fever, SARS, asian flu and others. Leak tightness of can be improved with an additional air bag. 


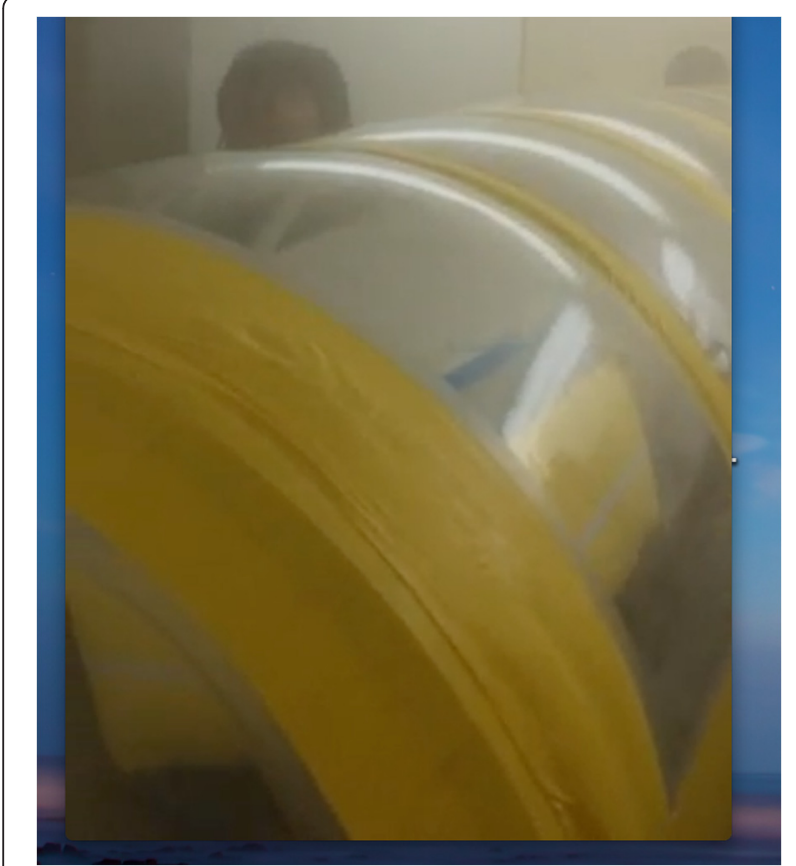

Figure 1 Over expanded single-patient isolation chamber during explosive decompression.

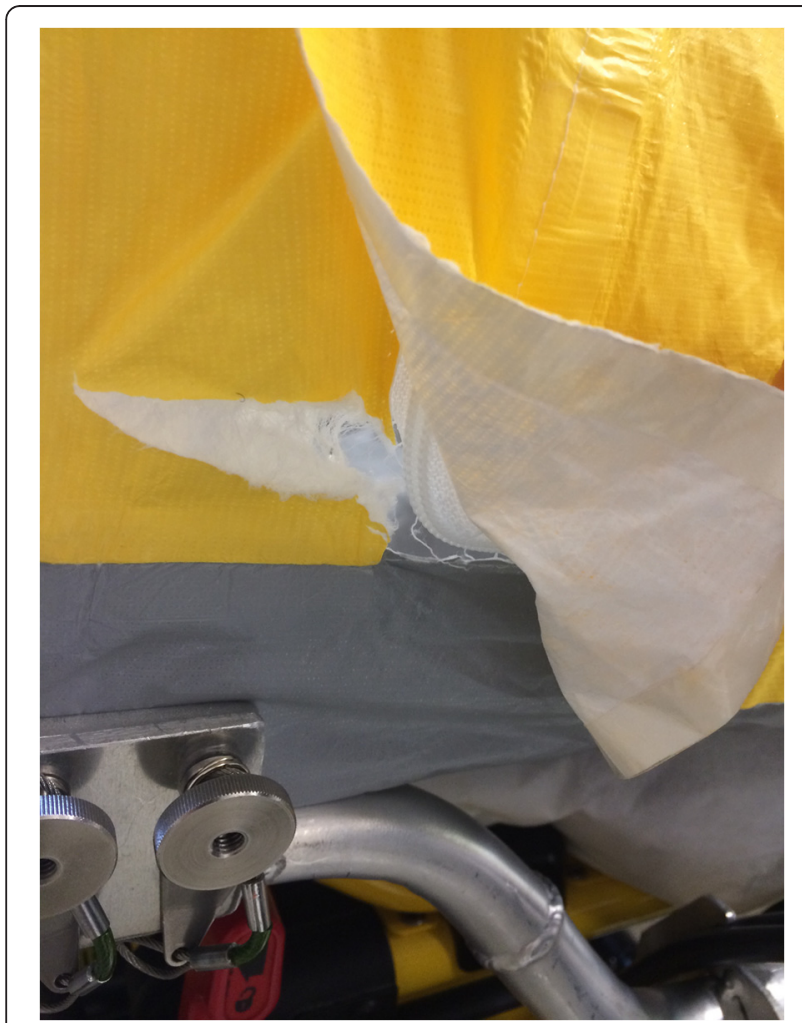

Figure 2 Ruptured suture after explosive decompression $(\Delta \mathrm{p} 493 \mathrm{hPa} / 7.15 \mathrm{Psl})$.

\section{Additional file}

Additional file 1: Videoclip demonstrating overexpansion of the isolation bag during explosive decompression.

\section{Competing interests}

RA applied for a patent addressing the reservoir air bag.

AK and WGV have no competing of interests.

\section{Authors' contributions}

AK and RA performed the experiment. WGV prepared the manuscript. All authors read and approved the final manuscript.

\section{Acknowledgement}

This study was supported in part by the Swiss Air Force, and the Swiss Air Rescue.

\section{Author details}

${ }^{1}$ Swiss Air Rescue, REGA, Zürich, Switzerland. 'Department of Anesthesiology, Kantonsspital, St. Gallen, Switzerland. ${ }^{3}$ Aeromedical Institute, Swiss Air Force, Dübendorf, Switzerland. ${ }^{4}$ Department of Anesthesiology and Critical Care Medicine, AUVA Trauma Center, Dr.-Franz-Rehrl-Platz 5, A-5010 Salzburg, Austria. ${ }^{5}$ ÖAMTC Austrian Air Rescue, Vienna, Austria. Innsbruck Medical University, Innsbruck, Austria. ${ }^{7}$ Paracelsus Private Medical University of Salzburg, Salzburg, Austria. ${ }^{8}$ Department of Health Studies, University of Stavanger, Stavanger, Norway.

Received: 17 December 2014 Accepted: 7 January 2015 Published online: 08 February 2015

\section{Reference}

1. Centers for Disease Control and Prevention; Guidance on Air Medical Transport for Patients with Ebola Virus Disease [http://www.cdc.gov/vhf/ ebola/healthcare-us/emergency-services/air-medical-transport.html]

\section{Submit your next manuscript to BioMed Central and take full advantage of:}

- Convenient online submission

- Thorough peer review

- No space constraints or color figure charges

- Immediate publication on acceptance

- Inclusion in PubMed, CAS, Scopus and Google Scholar

- Research which is freely available for redistribution 